\title{
Essay \\ If Law Professors Had to Turn in Time Sheets
}

\author{
Robert M. Jarvis†
}

Since January, the meinbers of the East Overshoe State Law School faculty have been required to keep a daily log of their professional activities. The following time sheet was submitted on April 19 by Professor Quentin T. Pomerantz.

10:45 a.m.

10:45-11:00 a.m.

11:00-11:05 a.m. Remembered it was "Doughnut Tuesday" in the faculty lounge. Went to faculty lounge intending to take a dozen (or so) home but discovered all doughnuts had been eaten. Made mental note to send e-mail to faculty secretaries reminding them doughnuts are for faculty members only.

11:05-11:45 a.m. Got into lengthy discussion with Professors Green and Johnson over lack of scholarly productiou by law school faculty. Discovered we all agree half the faculty is loafing, should be fired, 
and should have their salaries redistributed to the half that is working. Got into heated disagreement over which half is which. Started to leave but stayed to referee fistfight between Professors Green and Johnson. Had Professor Johnson ahead on points until Professor Green's KO. Made mental note to sit as far away as possible from Professor Green at future faculty meetings.

11:45-2:00 p.m. Went to faculty club for lunch. Dined with Professor Stone from the Business School. Discovered we both agree half the University faculty is loafing, should be fired, and should have their salaries redistributed to the half that is working. Got into fistfight with Professor Stone over which half is which. Made mental note to avoid eating at faculty club for next few weeks.

2:00-2:30 p.m. Prepared for class by looking for Teacher's Manual. Eventually remembered casebook does not have a Teacher's Manual. Made mental note to select different casebook next term.

2:30-4:00 p.m.

Taught Criminal Law class. Topic (according to casebook) was "Appeals." Discussed at length the appeal I am working on. Also discussed fact that if argument goes badly, this semester's grades will be delayed 3 to 5 years. Students seeined agitated. Made mental note not to discuss my personal life in class.

4:00-4:25 p.m. Went to mailroom to check my mail. Also checked colleagues' mail. Noticed Visiting Professor Stanza receives lots of interesting lingerie catalogs. Made mental note to invite Professor Stanza out for a drink.

4:25-4:45 p.m. While reading my mail, came across invitation to be keynote speaker at symposium in my priinary field of research. Conference to be held next February 17-20 in Iceland. All expenses to be paid by sponsor. Also received form letter announcing Honolulu Bar Association will be 
holding Recent Developments in Hawaiian Native Culture Law CLE program February 1720 . Cost for me to attend about $\$ 14,000$. Made mental note to discuss with law school's business manager my newly-acquired interest in Hawaiian Native Culture Law.

4:45-5:15 p.m. Continued reading my mail. Saw new issue of Eleemosynary Law Review (top journal in my field) had arrived. Carefully checked all footnotes im all articles to see if my book had been cited. Made mental note to cancel my subscription to $E L R$ in light of its recent decline in scholarship standards.

5:15-6:00 p.m. Met Dean for drink at local watering hole. Suggested my class load be reduced in light of my unusual productivity during past year. Dean suggested instead my paycheck be reduced in light of my unusual proclivities during past year. Decided to take my offer off the table. Made inental note to check with other faculty members to see if they agree Dean seems unusually hostile these days.

6:00-8:00 p.m. Attended law school alumni reception. Sampled various offerings from the bar. Explained (somewhat mcoherently) to current and former students my single-handed defense of their right to date faculty during last month's debate on proposed Code of Faculty Ethics. Before I could finish, shown door by two rather large waiters. Made mental note not to drink at these sorts of functions in the future.

8:00-10:00 p.m. Returued to my office. Re-read latest draft of my law review article Charitable Giving in Boston, 1820-1860: A Case Study in Early Altruism. Realized article is complete gibberish. Made mental note to fire research assistant who wrote it. 
10:00-10:30 p.m. Watched Gilligan's Island re-run on TV in faculty lounge. Still can't figure out how Professor is able to build a radio out of Gilligan's hat and two coconuts but can't get castaways off the island. Made mental note to apply for sabbatical to explore issue more fully.

10:30-10:45 p.m. Returned to my office. Again read over latest draft of law review article. Still complete gibberish. Decided to change title to Deconstructing the Shifting Paradigm: A Modernist, Post-Feminist Critique of the Spice Girls and Their Role in Post-Post-Industrial Society (With Apologies to Hegel). Sent article to Harvard Law Review. Acceptance seems likely. Made mental note not to fire research assistant.

10:45-11:00 p.m. Finished reading newspaper begun at breakfast. Noticed New York Yankees have given $\$ 22$ million contract to hitter with lifetime batting average of .177. Left law school to find all-night sporting goods store. Made mental note to ask clerk for location of nearest all-night batting cage.

Total Hours Worked: 13 (includes time spent dodging angry students in parking lot) 